\title{
Power Exchange Price Volatility Analysis after one year of Trilateral Market Coupling
}

\author{
C. De Jonghe ${ }^{1}$, L. Meeus ${ }^{1}$, R. Belmans ${ }^{1}$ \\ ${ }^{1}$ Katholieke Universiteit Leuven, Belgium \\ Dept. ESAT \\ Kasteelpark Arenberg, ${ }^{\circ} 10$ \\ 3001 Heverlee, Belgium \\ Phone: +3216321020 \\ E-mail: Cedric.DeJonghe@esat.kuleuven.be \\ Leonardo.Meeus@esat.kuleuven.be \\ Ronnie.Belmans@esat.kuleuven.be
}

\begin{abstract}
Keywords-Power exchanges, market coupling, volatility, reduction potential

Abstract-Trilateral Market Coupling (TLC) was launched in November 2006 in Belgium, France and the Netherlands. The initiative results in a sharp decrease of hourly price differences. This paper analyses whether the price convergence obtained, also reduced price volatility. Evidence for a significant price volatility reduction has only been found on APX. One possible explanation is given by introducing the volatility reduction potential based on the non- simultaneous occurrence of shocks.
\end{abstract}

\section{INTRODUCTION}

$\mathrm{P}$ rice volatility refers to the fluctuations of the price of an asset observed over a period of time. The spread of these fluctuations is a measure of the uncertainty of the future price. Whereas price volatility is related to the likeliness of any possible outcome, the price risk is more likely associated with an undesirable outcome.

Power markets are often said to be volatile, especially if hourly prices of power exchanges are considered. The volatility of power exchange prices has different drivers. These driving elements induce supply or demand shocks. The more abrupt a shock, the stronger the effect on the price level may be. The most pronounced shocks result in a sudden and extreme price increase or decrease, referred to as a spike.

In Europe day ahead trade is typically organized nationally by local exchanges. Arbitrage between exchanges has been possible for many years. Despite this possibility, price divergence often still remained, even in unconstrained cases. To solve this inefficiency, there is a tendency towards a coordinated clearing of exchanges. The resulting price differences, plotted in Fig. 1 between APX and Powernext, confirm a sharp increase in the frequency of hourly price convergence after the coupling of the markets.

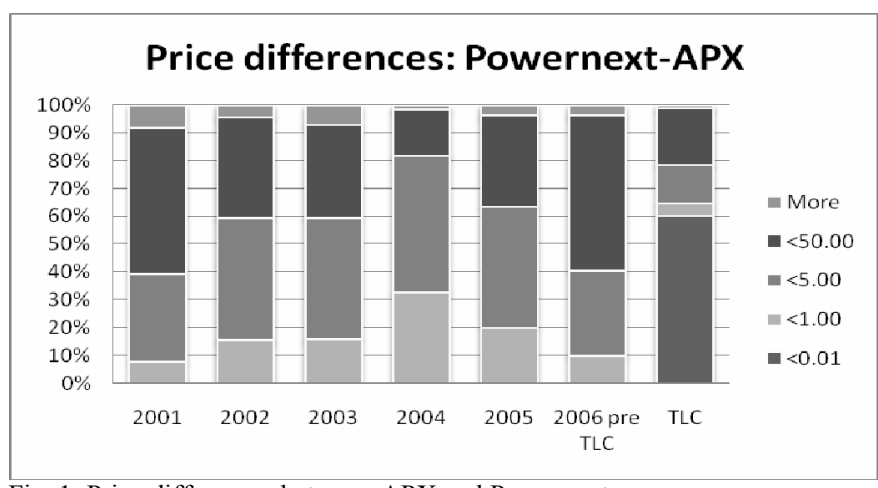

Fig. 1. Price differences between APX and Powernext

Although there was only price convergence in less than $1 \%$ of the cases before TLC, this level skyrocketed up to $60 \%$ after market coupling. This sharp increase in price convergence is the most prominent illustration of improved arbitrage.

Knowing that the market coupling has increased price convergence, it is the contribution of this paper to study the extent to which market coupling, also reduced price volatility. An overall price volatility reduction could be expected to the extent that supply or demand shocks on the different exchanges, as the result of volatility drivers, do not occur simultaneously. This concept is referred to as the volatility reduction potential.

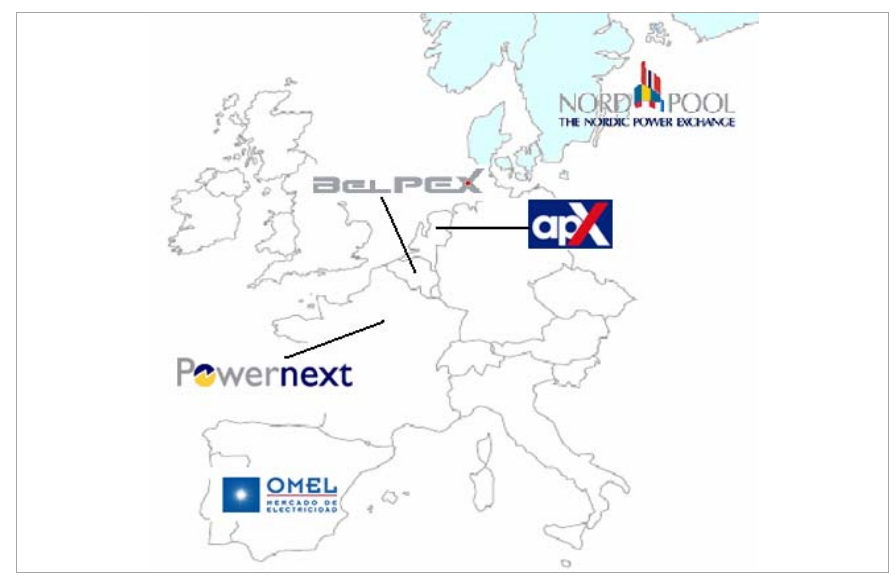

Fig. 2. Price differences between APX and Powernext 
Market coupling is done by Nord Pool Spot in the Nordic market, by APX, Belpex and Powernext in the Central Western European market and by Omel in the Iberian market MIBEL [5]. Only in Central Western Europe however, APX and Powernext operated independently, already before the socalled Trilateral Market Coupling (TLC) initiative. This substantiates why a meaningful pre/post analysis can only performed for APX and Powernext. Belpex was founded at the launch of TLC in the end of 2006.

The next section describes volatility with an outline of different volatility drivers and an index to measure volatility. This is followed in section three by stating the importance of the volatility reduction potential, based on the moment of extreme prices. After this the price volatility evolution due to the market coupling, the impact is calculated in section four, upon which a conclusion is drawn in the final section.

\section{Volatility}

A possible evolution in price volatility after the trilateral market coupling is investigated. Therefore it is necessary to first briefly describe volatility and its drivers and afterwards specify how this volatility can be measured.

\section{A. Volatility and its Drivers}

As indicated in the introduction volatility quantifies the degree of uncertainty on future electricity prices. This price tends to be far more volatile than that of other commodity markets [12] as illustrated on Fig. 3 for Powernext. Even though a remarkably volatile price pattern can be seen from 2002 until the end of the first year of TLC, even for the daily average prices. Fig. 3 shows that also with the softened average prices, several times the $€ 100 / \mathrm{MWh}$ level is crossed. The top-bottom vertical line indicates the launch of TLC in November 2006.

Power exchange price volatility can, among others, be driven by technical, economic and seasonal characteristics. Volatility drivers induce shocks, causing a shift of the supply or demand curve and a following price impact. Most often, it is linked with the non-storability [14] or the grid restrictions and its reliability [12]. On top of that, the authors in [4] and [12] respectively refer to diurnal patterns and weather conditions. Possible reactions by the transmission system operator to soften the impact of a volatility driver by disconnecting load or dispatching cold reserves, will not be considered.

Although it is not the authors' intention to give an exhaustive list of the different volatility drivers with the induced shocks, it is important to acknowledge that these could occur both simultaneously or non-simultaneously. This distinction is stressed in section III in the context of the volatility reduction potential.

\section{B. Measuring Volatility}

Therefore, price volatility has different drivers. Strong price volatility has also been illustrated in Fig. 3 .

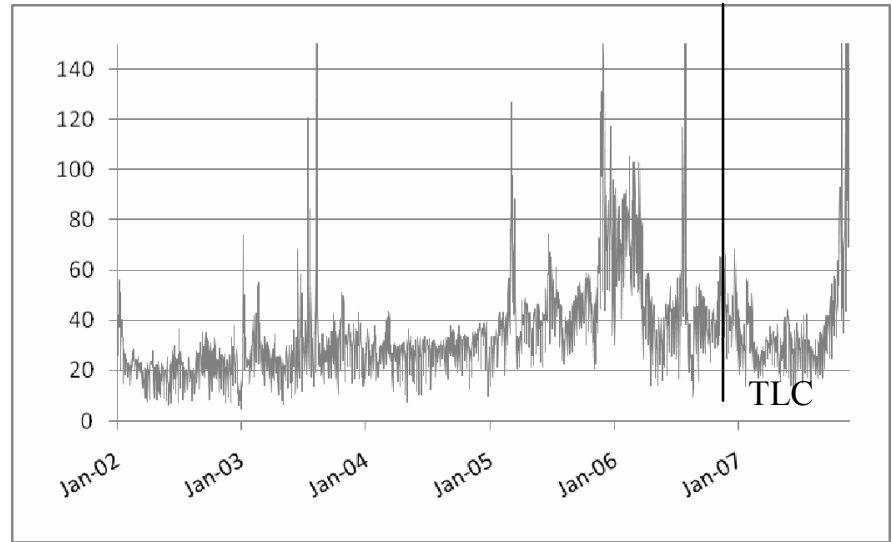

Fig. 3. Volatile price behavior of average daily prices on Powernext

To perform an objective volatility comparison, it is necessary to be able to measure price volatility. Price volatility is often measured as the standard deviation of logarithmic, in [15] applied on Omel, or arithmetic returns. The author in [11] explains his preference for the logarithmic return and even in [13] the authors use the logarithmic return and refer to it as the historical volatility. This standard deviation could however be fully dominated by the return as a result of one single extreme upward or downward spike. Two curves are plotted in Fig. 4 to illustrate the possible dominating impact. The curve "Powernext" shows the volatility based on the commonly used logarithmic standard deviation for Powernext for one year ${ }^{1}$ for each hour separately. The second curve "Powernext ${ }^{2}$ " uses the same index, based on the same data, except that one day is eliminated. Notwithstanding the fact that only one day is eliminated, this has an enormous effect on the first six and last two hours.

After elimination, the calculated standard deviation decreased by a factor two in the mentioned morning hours and even by a factor four in late night hours from above 0.6 to below 0.2. This sharp deviation is the impact of low prices on Powernext on April $28^{\text {th }}$ 2007. Prices tumbled below $€ 1 / \mathrm{MWh}$ for the hours mentioned. As a consequence, the authors conclude not to use this index in this paper.

This problem can be solved by the daily velocity (DV) index, calculated in [13] to quantify price uncertainty. In [3] the authors use the velocity concept together with the abovementioned standard deviation to compare 14 liberalized markets. Price differences are divided by the daily average (DA) price instead of the previous price level as in the logarithmic return calculations. The impact of a single extremely low or high price level is strongly reduced.

$$
D V D A_{\Delta t}=\frac{|P(t)-P(t-\Delta t)|}{\text { Daily Average of } P(t)}
$$

Although the dominating impact of extreme price levels is softened, they still strongly influence the calculated price velocity. However this is not a problem as these price levels remarkably deviate from the average price level, which must be reflected by a volatility index.

\footnotetext{
${ }^{1}$ The First year of TLC is used from November 22th 2006 until November 21 th 2007. This includes 365 prices for every hour.
} 


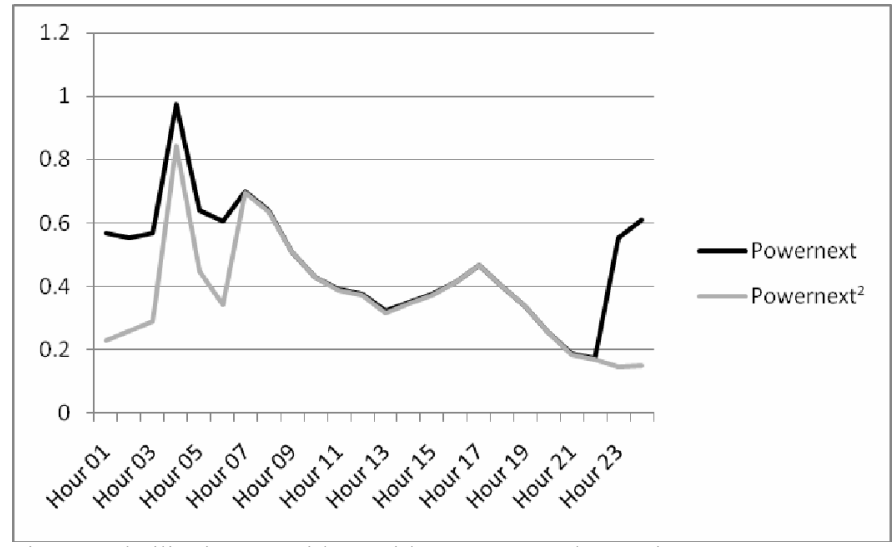

Fig. 4. Volatility impact with or without extreme observation

\section{VOLATILITY REDUCTION POTENTIAL}

Preceding section enumerates drivers and an index to measure volatility. The volatility drivers induce a supply or demand shock with a resulting impact on the price level. It is important to see a shock as the cause and the price effect as the result on the power exchange. This section stresses the importance of moment of occurrence of shocks on different exchanges. Based on the non-simultaneous occurrence, a volatility reduction potential is found.

\section{A. (Non-) Simultaneous Shocks}

Shocks may occur simultaneously or not. Simultaneous shocks on different exchanges are the result of correlated occurrence of volatility drivers (for instance a cold spell in Western Europe). On the other hand, non-simultaneous shocks can be seen as the result of uncorrelated occurrence of volatility drivers (for instance a national holiday). Fig. 5 illustrates the concept of shock occurrence for prices on Powernext (left) and APX (right) for July 2006 as an example. Three full lines point out three shocks that occur simultaneously. On the other hand also shocks can be found that do not occur simultaneously (encircled in Fig. 5).

In a real situation, seasonal volatility drivers often occur in correlated order and technical volatility drivers such as sudden plant outages or interconnection failures will happen in an uncorrelated order.
Due to the uncorrelated nature of a volatility driver, a shock does not happen simultaneously on different exchanges. As a result, the price impact on one exchange can be compensated by another, unaffected exchange. Further in this paper, only simultaneous or non-simultaneous shocks are discussed. The fact whether or not volatility drivers occur in a correlated way is no longer addressed explicitly, but considered as the underlying influence.

If sufficient transfer capacity is available, prices of coupled power exchanges converge. In case of a very large price difference between exchanges, the price difference is only reduced until the transfer capacity is fully used. This situation is in contrast with the inefficiency in arbitrage due to time lags between the border capacity auctions and the exchanges for the Benelux region before TLC [7].

The extent to which shocks do not occur simultaneously, indicates the opportunities for compensating the price impact of such a non simultaneous shock and therefore illustrates the volatility reduction potential. Even though the nonsimultaneous occurrence, calculated below, might be slightly more difficult to understand than the simultaneous occurrence, the first can directly be associated with a price volatility reduction potential.

It is important to distinguish the different characteristics of following two extreme price indicators: percentile values and spikes. The percentile values report the most extreme prices in terms of percentage. First a percentage level is chosen. Based on that, the price level will be given above which the other extreme prices as a percentage of all observed price levels can be found. The price level only crossed in $1 \%$ of the cases refers to the $99 \%$ percentile value. It thus happens 87 hours out of 8760 per year. As a result, the percentile value differs most of the time for different exchanges (Fig. 5). As an example, a percentile value $99.5 \%$ is calculated, referring to the 43 highest price levels. The price rose for 43 times above $€ 305 / \mathrm{MWh}$ on APX and above $€ 207 / \mathrm{MWh}$ on Powernext, indicated by the dashed horizontal line.

The spikes index on the other hand is based on a fixed, arbitrary chosen price level and counts how often the price level on the exchanges crosses the particular price level. This

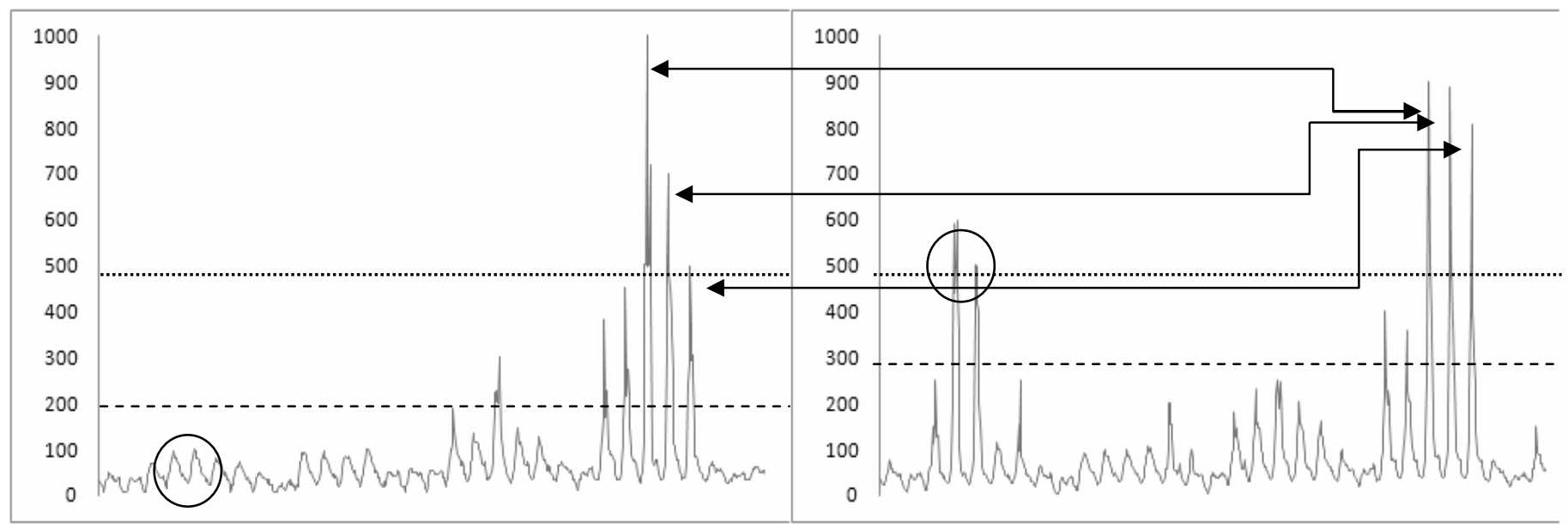

Fig. 5. (Non-)Simultaneous shock occurrence on Powernext (left) and APX (right) - July2006 
is illustrated by the dotted line for the arbitrary chosen $€ 500 / \mathrm{MWh}$ level in Fig. 5. Analogous lines can be drawn for the lowest price levels.

The market resilience, used as a liquidity measure to indicate the price impact of a supplementary order, could also give an idea of the volatility reduction potential. Since market resilience is only analyzed by Belpex and Powernext, the potential can not be compared between APX and Powernext. The impact of a supplementary order is however expected to be larger on a smaller market. As a consequence, a larger volatility reduction potential after market coupling is expected on the smaller exchange.

\section{B. Non simultaneous occurrence of percentile values}

The volatility reduction potential is first illustrated in TABLE I by the percentage of non simultaneous occurrence of the most extreme price levels. This corresponds to the number of hours when the price exceeds a level calculated in terms of percentage simultaneously, divided by the total number. As mentioned above, this total number equals for both exchanges e.g. 87 for $99^{\text {th }}$ percentile value. One table of non simultaneous occurrence is therefore calculated for both exchanges and no distinction can be made between APX and Powernext. A higher percentage is considered to result in a higher potential to reduce volatility.

From 2002 until 2006 i.e. pre TLC, the calculated percentages are given in TABLE I. Those percentages are on average relatively high. All situations with a non simultaneous occurrence above $80 \%$ are marked. Although this level is arbitrarily chosen, it becomes evident that extremely high price levels happen less simultaneously than in case of low price levels. This suggests that there is a significant volatility reduction potential and especially for upward price evolutions.

\section{Non simultaneous occurrence of spikes}

A potential for volatility reduction by market coupling is presumed based on the high percentages in TABLE I. It was however impossible to make a distinction between the potential for different exchanges. The volatility reducing potential can also be demonstrated by the non simultaneous spike occurrences. Two different percentages are found in this case, as the number of non simultaneous spikes is divided by the total number of crossing a particular price level, referred to as a spike. Since this total number of spikes differs between both exchanges, the calculated percentage also differs. Therefore, the index also considers the total number of price spikes, neglected by the percentile value measure. Consequently, it is now possible to calculate a different volatility reduction potential for both exchanges.

The number of non simultaneous spikes, relative to the total number of spikes for APX and Powernext respectively, are plotted for both up- and downward spikes in TABLE II and TABLE III. $0 \%$ non simultaneous occurrence indicates that each occurring spike also took place on the other exchange. A blank space in TABLE II or TABLE III however refers to no presence of spikes at all.
TABLE I

NON SIMULT ANEOUS OCCURRENCE OF PERCENTILE VALUES

\begin{tabular}{lcccccccc}
\hline \hline YEAR & $0.1 \%$ & $0.2 \%$ & $0.5 \%$ & $1.0 \%$ & $99.0 \%$ & $99.5 \%$ & $99.8 \%$ & $99.9 \%$ \\
\hline 2002 & $78 \%$ & $67 \%$ & $70 \%$ & $69 \%$ & $\mathbf{8 7 \%}$ & $\mathbf{9 1 \%}$ & $\mathbf{1 0 0 \%}$ & $\mathbf{1 0 0 \%}$ \\
2003 & $44 \%$ & $67 \%$ & $73 \%$ & $67 \%$ & $79 \%$ & $\mathbf{8 4 \%}$ & $61 \%$ & $78 \%$ \\
2004 & $\mathbf{8 9 \%}$ & $67 \%$ & $45 \%$ & $48 \%$ & $\mathbf{9 1 \%}$ & $\mathbf{9 5 \%}$ & $\mathbf{1 0 0 \%}$ & $\mathbf{1 0 0 \%}$ \\
2005 & $33 \%$ & $56 \%$ & $52 \%$ & $52 \%$ & $70 \%$ & $\mathbf{8 0 \%}$ & $78 \%$ & $\mathbf{8 9 \%}$ \\
2006 pre & $\mathbf{8 9 \%}$ & $\mathbf{8 3 \%}$ & $70 \%$ & $57 \%$ & $53 \%$ & $61 \%$ & $61 \%$ & $56 \%$ \\
TLC & & & & & & & & \\
\hline \hline
\end{tabular}

TABLE II

APX: NON SIMULTANEOUS OCCURRENCE OF SPIKES

\begin{tabular}{lccccc}
\hline \hline YEAR & $\#>=250 €$ & $\#>=500 €$ & $\#>=750 €$ & $\#>=1000 €$ & $\#>=1250 €$ \\
\hline 2002 & $\mathbf{1 0 0 \%}$ & $\mathbf{1 0 0} \%$ & & & \\
2003 & $93 \%$ & $91 \%$ & $77 \%$ & $65 \%$ & $100 \%$ \\
2004 & $\mathbf{1 0 0 \%}$ & $\mathbf{1 0 0 \%}$ & $\mathbf{1 0 0} \%$ & & \\
2005 & $90 \%$ & $96 \%$ & $100 \%$ & $100 \%$ & \\
2006 pre & $64 \%$ & $75 \%$ & $75 \%$ & & \\
TLC & & & & & \\
\hline \hline
\end{tabular}

POWERNEXT: NON SIMULTANEOUS OCCURRENCE OF SPIKES \begin{tabular}{llllll}
\hline \hline YEAR & $\#>=250 €$ & $\#>=500 €$ & $\#>=750 €$ & $\#>=1000 €$ & $\#>=1250 €$ \\
\hline
\end{tabular} 2002

$2003 \quad 32 \% \quad 13 \% \quad 0 \% \quad 0 \%$

$2004 \quad 47 \% \quad 67 \%$

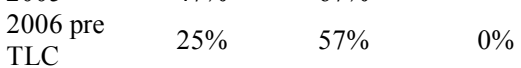

TABLE III

APX: NON SIMULTANEOUS OCCURRENCE OF SPIKES

\begin{tabular}{lccccc}
\hline \hline YEAR & $\#<=5 €$ & $\#<=4 €$ & $\#<=3 €$ & $\#<=2 €$ & $\#<=1 €$ \\
\hline 2002 & $90 \%$ & $91 \%$ & $97 \%$ & $100 \%$ & $100 \%$ \\
2003 & $84 \%$ & $81 \%$ & $88 \%$ & $87 \%$ & $87 \%$ \\
2004 & $71 \%$ & $74 \%$ & $70 \%$ & $94 \%$ & $95 \%$ \\
2005 & $\mathbf{1 0 0 \%}$ & $\mathbf{1 0 0 \%}$ & $\mathbf{1 0 0} \%$ & $\mathbf{1 0 0 \%}$ & $\mathbf{1 0 0 \%}$ \\
2006 pre & $88 \%$ & $95 \%$ & $98 \%$ & $95 \%$ & $100 \%$ \\
TLC & POWERNEXT: NON SIMULTANEOUS OCCURRENCE OF SPIKES \\
\hline \hline YEAR & $\#<=5 €$ & $\#<=4 €$ & $\#<=3 €$ & $\#<=2 €$ & $\#<=1 €$ \\
\hline 2002 & $22 \%$ & $17 \%$ & $43 \%$ & $80 \%$ & $100 \%$ \\
2003 & $44 \%$ & $44 \%$ & $48 \%$ & $50 \%$ & $50 \%$ \\
2004 & $27 \%$ & $40 \%$ & $31 \%$ & $75 \%$ & $83 \%$ \\
2005 & & & & & \\
2006 pre & $31 \%$ & $50 \%$ & $75 \%$ & $50 \%$ & $100 \%$ \\
TLC &
\end{tabular}

It is obvious that the percentage of non simultaneous spikes is higher on APX. In 2002 and 2004 spikes above $€ 250 / \mathrm{MWh}$ did not occur on Powernext and were therefore $100 \%$ non simultaneous on APX.

This phenomenon also took place in 2005 (TABLE III). Besides 2005, the percentage of non simultaneous downward spikes was also in the other years much higher on APX. Therefore, a higher potential for volatility reduction can be found on the Dutch power exchange than on Powernext.

\section{Price volatility evolution}

The occurrence of the most extreme price fluctuations has been investigated to conclude a price volatility reduction potential. This section studies the price volatility evolutions for APX and Powernext using the suggested method in section 
II. Based on the results, conclusions are drawn in section V whether or not the potential for a volatility reduction is fulfilled.

An expected and unexpected price velocity can be distinguished. The expected price velocity arises from the average daily pattern of price velocity (DVDA) (1). It is however the unexpected velocity, measured by the standard deviation of price velocity that most appropriately indicates the price velocity. As can be seen from (1), different $\Delta t$ interval periods can be considered. An hourly profile is plotted for the last four years in Fig. 6 till Fig. 9. Only the interval periods $\Delta \mathrm{t}=1 \mathrm{~h}$ and $\Delta \mathrm{t}=24 \mathrm{~h}$ are given referring to an hourly price velocity with an interval of respectively one hour and one day. The pattern for interval periods $24 \mathrm{~h}$ and $168 \mathrm{~h}$ (one week) are rather similar.

The first noticeable aspect is that the standard deviation of price fluctuations with an interval of 1 hour is on average much smaller than with a $24 \mathrm{~h}$ interval. Above that, the overlapping of the different curves in the morning hours is remarkable. Furthermore, the daily load profile can be recognized in the velocity standard deviation for the $24 \mathrm{~h}$ interval for both exchanges with pronounced noon and evening spike.

Comparing the last 4 years standard deviation of price velocity decreased significantly on APX since TLC. This decrease is most remarkable for price fluctuations based on a one-hour intervals. Extreme evening peaks in 2004 and 2005 in Fig. 6 and both noon and evening peaks in Fig. 7 are reduced. A lower price volatility is not found on Powernext after TLC in Fig. 8 and Fig. 9. Although the volatility level is comparable with previous years, Powernext witnessed for both Fig. 8 and Fig. 9. remarkable evening volatility increases. This is in contrast with APX data.

This price volatility increase during the evening is strongly influenced by exceptional market circumstances in France from end October until November. French total nuclear power generation faced an outage of about 20 percent during the extremely cold November in 2007. Although volatility drivers of technical nature have been considered as uncorrelated, for which mutual compensation could be expected, the outage was too large so that almost no softening could be seen. These circumstances have a strong impact on the French market. This is the risk of drawing conclusions based on only one year of market data.

\section{CONCLUSIONS}

This paper evaluates a possible evolution in the price volatility after market coupling on APX and Powernext. To perform this analysis, the most commonly used volatility index is extended and fine tuned in order to avoid that only a few extreme prices can influence significantly the volatility index based on the standard deviation of the logarithmic return.

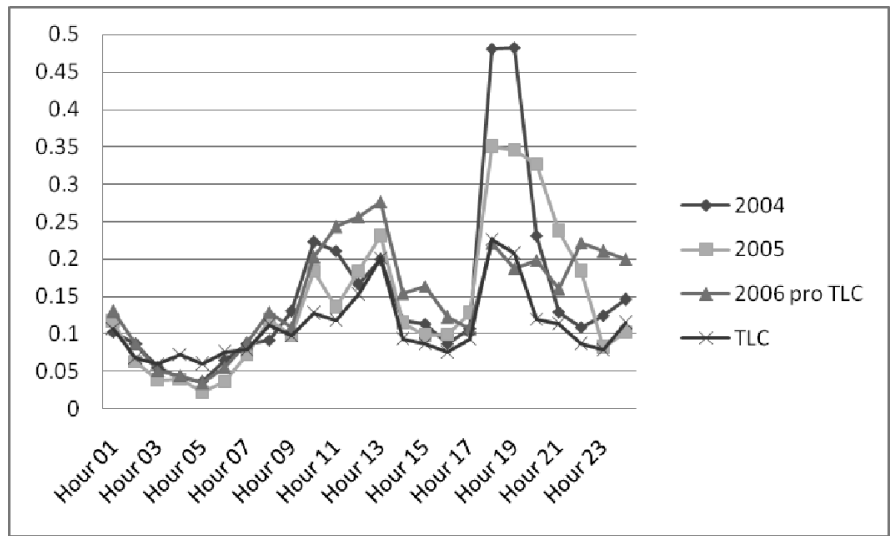

Fig. 6. APX: Standard deviation of price velocity $\Delta \mathrm{t}=1 \mathrm{~h}$

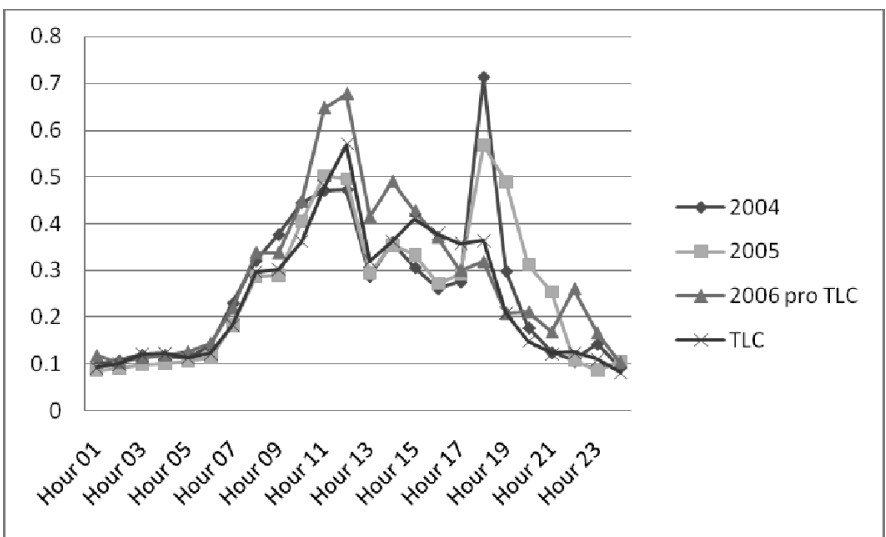

Fig. 7. APX: Standard deviation of price velocity $\Delta \mathrm{t}=24 \mathrm{~h}$

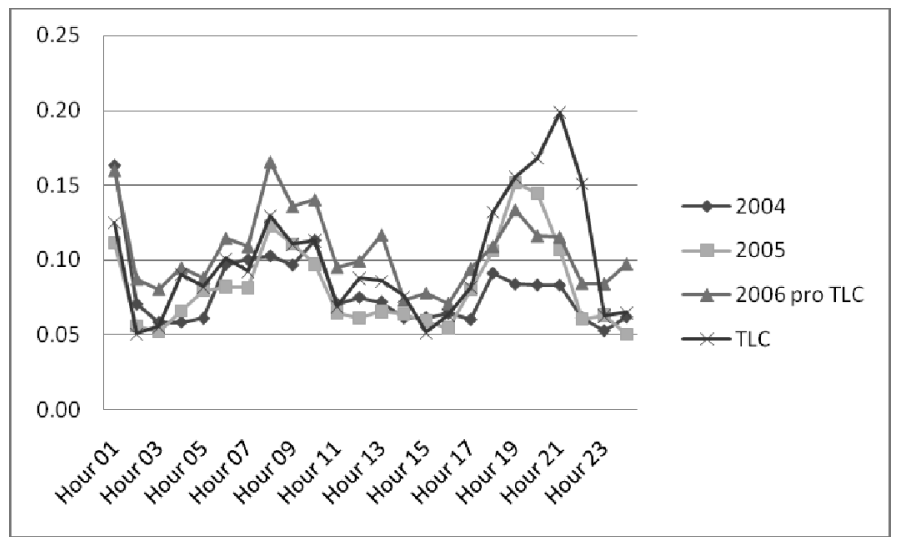

Fig. 8. Powernext: Standard deviation of price velocity $\Delta \mathrm{t}=1 \mathrm{~h}$

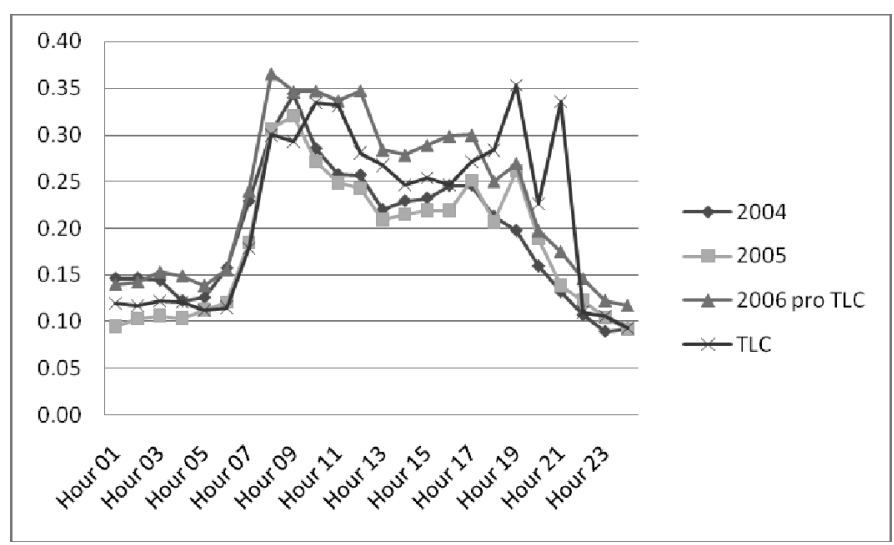

Fig. 9. Powernext: Standard deviation of price velocity $\Delta \mathrm{t}=24 \mathrm{~h}$ 
A price volatility reduction potential is defined by studying the hour of extreme price occurrence, based on the idea of a mutual compensation potential. The reduction potential is determined generally by the percentile values and by the non simultaneous occurrence of price spikes to make a distinction between APX and Powernext. A more pronounced volatility reduction potential may be expected for APX.

Finally, a volatility reduction is calculated on APX after market coupling. TLC had however no volatility reducing impact on Powernext.

One of the possible explanations for the abovementioned contradiction is illustrated, albeit that only one year of data is available since the start of TLC. The concept of potential of volatility reduction is introduced. It is stressed that supply and demand shocks manifest themselves by extreme prices. The more shocks occur on one exchange in a more uncorrelated order, the more non simultaneous extreme prices appear. Due to this non simultaneous nature, there exist an opportunity for a mutual compensation performed through arbitrage. This explains the differences in potential of volatility reduction, apparent on both APX and Powernext.

\section{ACKNOWLEDGMENTS}

This research was performed with support of Belpex, APX and Powernext, respectively the Belgian, Dutch and French power exchange.

The research at the KU Leuven is performed within the framework of the research program 'InterDisciplinaire Onderzoeksprogramma's ' (IDO) and financially supported by the Belgian 'Fonds voor Wetenschappelijk Onderzoek (F.W.O.)-Vlaanderen'.

\section{REFERENCES}

[1] WW. Hogan, "A market power model with strategic interaction in electricity networks," The Energy Journal, Vol. 18, no. 4, pp. 107-141, 1997.

[2] D. Hurlbut et al. "Protecting the market from "hockey stick" pricing: How the Public Utility Commission of Texas is Dealing with Potential Price Gouging," The Electricity Journal, Vol. 17, no. 3, pp. 26-33, Apr. 2004.

[3] Y. Li and PC. Flynn (a), "Deregulated power prices: comparison of volatility," Energy Policy, Vol. 32, no. 14, pp. 1591-1601, Sept. 2004.

[4] Y. Li and PC. Flynn (b), "Deregulated power prices: comparison of diurnal pattern,". Energy Policy, Vol. 32, no. 5, pp. 657-672, Mar. 2004.

[5] L. Meeus, R. Belmans, "Electricity Market Integration in Europe," unpublished.

[6] D. Newbery, NH von der Hehr and E. van Damme. (May 2003). Liquidity in Dutch wholesale electricity market. available: http://www.dte.nl/images/12_8760_tcm7-596.pdf.

[7] K; Purchala, L. Meeus and R. Belmans. (2004). The analysis of the cross-border capacity allocation in the Benelux Region. Available: http://www.esat.kuleuven.be/electa/publications/fulltexts/pub_1265.pdf.

[8] K. Neuhoff, Integrating Transmission and Energy Markets Mitigates Market Power, Cambridge DAE, 2003.

[9] AS. Siddiqui, C. Marnay and M. Khavkin, "Excessive Price Volatility in the California Ancillary Services Markets: Causes, Effects and Solutions," The Electricity Journal, Vol. 13, no. 6, pp. 58-68, Jul. 2000.

[10] I. Simonsen et al. (2004). Structure and stylized facts of a deregulated power market. Unpublished. Available: http://mpra.ub.unimuenchen.de/ 1443 .

[11] I. Simonsen, "Volatility of Power markets," Physica A: Statistical Mechanics and its Applications, Vol. 355, no.1, pp. 10-20, Sept. 2005.

[12] R. Weron, "Energy price risk management," Physica A: Statistical Mechanics and its Applications, Vol. 285, no. 1-2, pp. 127-134, Sept. 2000 .
[13] H. Zareipour, K. Bhattacharya and CA. Canizares, "Electricity market price volatility: The case of Ontario," Energy Policy, Vol. 35, no. 9, pp. 4739-4748, Sept. 2007.

[14] E. Escribano., J.I. Pena and P. Villaplana. (June 2002). Modeling electricity prices: International evidence, Working paper 02-27, Universidad Carlos III de Madrid. Available: http://docubib.uc3m.es/WORKINGPAPERS/WE/we022708.pdf.

[15] M. Isabel and R. T. Soares. (2004). Restructuring of the European Power Industry: Market Structure and Price Volatility, University of Porto.. Available: http://www.sessa.eu.com/documents/wp/D23.2_Soares.pdf.

Cedric De Jonghe received the M.S. degree in commercial engineering in 2007 from the Katholieke Universiteit Leuven (K.U.Leuven). He is a member of the KULeuven Energy Institute and of the Electrical Energy research group (ELECTA) of the department of Electrical Engineering of the KULeuven, where he is working towards a Ph.D. on electricity market design. His research interests include techno-economic aspects of power systems, electricity markets and security of supply.

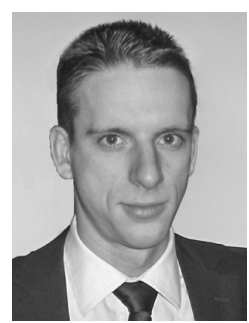

Leonardo Meeus (M'06) received the M.S. degree in commercial engineering in 2002 and the Ph.D. degree in electrical engineering in 2006, both from the KULeuven, Belgium. Currently, he is a senior researcher of the KULeuven Electric Energy Research Group ELECTA. His research interests include liberalization, security of supply and sustainability. $\mathrm{He}$ is also the scientific coordinator of the KULeuven Energy Institute and the European Energy Institute (EEI). Since 2006, he is the chairman of the CIGRE Task Force C5-7.1 on generation and network capacity investment incentives in electricity markets.

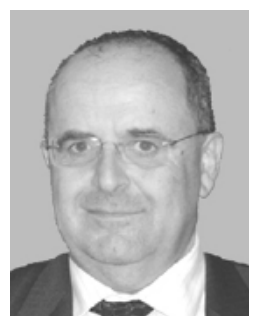

Ronnie Belmans (M'84-SM'89-F'05) received the M.S. degree in electrical engineering in 1979, the Ph.D. in 1984, and the Special Doctorate in 1989 from the K.U.Leuven, Belgium and the Habilitierung from the RWTH, Aachen, Germany, in 1993. Currently, he is full professor with K.U.Leuven, teaching electrical machines and variable speed drives. He is appointed visiting professor at Imperial College in London. He is also President of UIE. He was with the Laboratory for Electrical Machines of the RWTH, Aachen, Germany (Von Humboldt Fellow, Oct.'88-Sept.'89). Oct.' 89 -Sept.' 90 , he was visiting associate professor at Mc Master University, Hamilton, Ont., Canada. During the academic year 1995-1996 he occupied the Chair at the London University, offered by the Anglo-Belgian Society. Dr. Belmans is a fellow of the IEEE and the IEE (United Kingdom). He is the chairman of the board of Elia, the Belgian transmission grid operator. 